\title{
The Rocker Bogie Mechanism: Design and Fabrication
}

\author{
Pushkar Patil ${ }^{1}$, Shubham Bhokardole ${ }^{2}$, Dhiraj Bhandarkar ${ }^{3}$ \\ ${ }^{1,2}$ UG Student, Mechanical Engineering Department \\ SVKM's Institute of Technology Dhule, India \\ ${ }^{3}$ Assistant Professor, Mechanical Engineering Department \\ SVKM's Institute of Technology Dhule, India
}

\begin{abstract}
The Rocker bogie mechanism is a mechanism primarily used in Mars's rovers to overcome the rough terrains while maintaining stability. The rocker-bogie mechanism is just like a climbing robot-type mechanism. It is NASA's important mechanism for space vehicles \& rovers. Rocker bogie has the simplest design and the number of wheels is also less. The model is made to travel the obstacle up to a tilting angle of $35^{\circ}$. This enables to have a suspension-based mechanism that distributes the vehicle load evenly not only on regular but also on bumps and irregular surfaces. The design consists of a spring-free suspension-based differential drive system that allows the bogie to move over rocks, pebbles, and some obstacles. The main gun mechanism adjustment is done with help of a 30 RPM and 60 RPM gear motor and with help of a compressed spring. As the tank's main gun mechanism rotates $360^{\circ}$ just like our steel shaft will rotate, so it becomes very easy to throw the ball at any degree angle, and as the project will move on a rough surface like a military tank so it will give military application (Defense Purpose). The main gun mechanism rotates one or more steel sprockets which move a track made up of hundreds of metal links.
\end{abstract}

Keywords- Rocker Bogie, Main Gun, Arduino, Relay Driver

\section{I- INTRODUCTION}

W e got this idea from NASA, as it is the design developed by NASA in the year 1988; the mechanism was developed for Mars, due to its environment to get more information about Mars. It is the design which is having its all six wheels are in touch with the ground or simply they are in touch with the surface. It is consisting of two arms with a wheel mounted to each. Rocker bogie mechanism is spring-less and stubs axles in each wheel to allow over any obstacles. Rocker means a larger link on each side of the suspension system. Bogie means smaller links that connect to the middle and drive wheel at each end. Basically, it is designed for smooth as well as rough surfaces. This mechanism has all six wheels are touched on the ground equally. The front wheels of the mechanism will be working for overcoming the obstacles coming in their path or route, the middle wheels will be working for getting the rear wheels in work, as the motion will be transferred from front to middle and then rear wheels. The main purpose behind initiations of this mechanism is to grasp mechanical design and the benefits of rocker-bogie suspension system for finding the suitability in conventional loading vehicles to enhance their efficiency and also to down the maintenance cost related to expenses of conventional systems. Here the advancement is done on the upper part of the rocker-bogie that is the main gun mechanism (just like a military tank) the main gun mechanism is throwing a ball with the help of a 30 RPM DC gear motor. The ball is playing the role of ammunition as in the tank. With the help of a controller, it is movable in a 


\section{International Journal of Innovations in Engineering and Science, www.ijies.net}

$360^{\circ}$ manner. We can throw a ball as per our requirement in any direction.

\section{II- LITERATURE REVIEW}

D.S. Chinckar, S.S.Gajghate, R.N.panchal, R.M.Shetenawar and P.S.Mulik (year 2017) published a paper in that paper they stated their views on the development of 3D Cad model of rocker-bogie mechanism and about the performance of rocker-bogie at different stages means in different positions. [1]

B.Babu, N.Dhayanidhi, S.Dhamotharan (year 2018) published a paper in that paper they stated their views about the selection of wheel and about the design calculations for suitable dimensions. [2]

Abhisek Verma, Chandrajeet Yadav, Bandana Singh, Arpit Gupta, Jaya Mishra, Abhishek Saxena, (year 2017) published a paper in that paper they explained about the history of rovers, use of rovers for NASA then detailed information about rocker-bogie mechanism and design of components which are required for rocker-bogie mechanism. [3]

Hafeezur Rahman, Ameer Malik Shaik, J. Rajesh Kumar, V. Balaguru, and P. Sivakumar, (year 2017) published a paper in that paper they stated their views regarding the various parameters present in the tank, the working of each respected part with detailed drawings. They have also explained the angle of the main gun mechanism with its mobility and flexibility. [4]

Abhaykant Sinha, Reshma Sinha (year 2018) published a paper in that paper they explained the structure of the rocker-bogie mechanism in a detailed manner according to both links of rocker and bogie part. How the load on the rocker-bogie is distributed on each wheel and how it overcomes the obstacle is mentioned clearly. [5]

S. F. Toha, Zakariya Zainol (year 2015) published a paper in that paper they stated their views for a rockerbogie mechanism which will be helpful at the time of disaster for providing service to people just like flood condition. Here they have focused on the term pressure specifically which will come when the rocker-bogie mechanism will travel on the road which is fully occupied by water. [6]

M. Vighneshwaran, R. Siddharthaa, G. Vijay and S. Pravin Kumar (year 2019) published a paper in that paper they stated their views about how should be the wireless control system of rocker-bogie mechanism with help of Arduino, Relay and RF Transmitter and Receiver adjustments. [7]

\section{III- COMPONENTS USED}

\section{1) PVC Pipe:}

- Pipe used as supporting link for rocker bogie

2) Wheel:

- Plastic wheel is used for movement of rocker bogie mechanism

- Dimension of wheel are $40 \times 70 \times 40 \mathrm{~mm}$

- $6 \mathrm{~mm}$ diameter is provided for gear motor arrangement

3) Sheet:

- Foam sheet is used for connecting two supporting links (Dimensions - 450×450 mm)

- Wooden sheet of main gun mechanism is mounted on the foam sheet (Dimensions $-250 \times 250 \mathrm{~mm}$ )

4) Shaft:

- Steel material shaft is used for throwing the ball in main gun mechanism

- Dimensions of shaft are $12 \mathrm{~mm}$ in diameter and 350 $\mathrm{mm}$ in length

5) Spring:

- Spring is placed in shaft for throwing the ball

6) Arduino Nano:

- Type: Micro Controller Board

- Material: Carbon Fibre

- Operating Voltage: 5V

- Analog Input Pins: 8

- Clock Speed: $16 \mathrm{MHz}$

7) Relay:

-10A effective VCC, GND power input

- 5V 4-channel control by microcontroller

- Operating Voltage: 5V DC

8) Gear Motor:

- RPM: 30, 45 and 60

- Operating Voltage: 12V DC

- No-Load Current: $60 \mathrm{~mA}$

9) Battery:

- Three batteries are used in project in series connection

- Operating Current: $1.5 \mathrm{~A}$

- Operating Voltage: 4V

10) RF Transmitter and Receiver:

- Wireless Transmitter and Receiver is used

- Transmission range is $3 \mathrm{~m}$

- Supply Current: $3.5 \mathrm{~mA}$

- Operating Voltage: 5V DC (for receiver)

- Operating Voltage: 9V DC (for transmitter)

\section{IV-CONTROL SYSTEM}

Here in this project for controlling of rocker-bogie mechanism is done with help of a wireless RF transmitter and receiver, the transmission range is $3 \mathrm{~m}$. 


\section{International Journal of Innovations in Engineering and Science, www.ijies.net}

All the DC gear motors are powered with help of a $12 \mathrm{~V}$ battery (4V each battery). For controlling the power of motors, the relay module is used and to connect the transmitter and relay module the Arduino board is used. Hence by doing all arrangements we can control the rocker-bogie mechanism and we can use it as per our need easily in various sections and also in military applications.

\section{V- ACTUAL MODEL PICTURE}

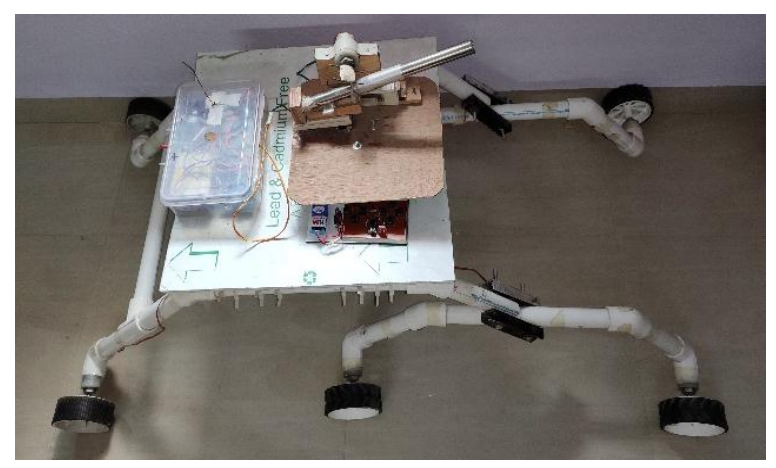

Fig 1- Rocker Bogie Mechanism

\section{VI- RESULTS}

The rocker-bogie mechanism is designed for a demonstration on the ground and it is tested successfully. By doing calculations and testing the actual model we get torque $\mathrm{G}=0.49032 \mathrm{Nm}$ for $45 \mathrm{RPM}$ gear motors which are planted on wheels, $\mathrm{G}=0.19611 \mathrm{Nm}$ for 30 RPM and $\mathrm{G}=0.19612 \mathrm{Nm}$ for $60 \mathrm{RPM}$ gear motor of main gun mechanism, which is meeting near to our expected torque. And about the main gun mechanism, there also we found the results satisfactory to our level hence we found these results are satisfactory for our project work.

\section{VII- CONCLUSION}

The main aim behind making this project is to show how the rocker-bogie mechanism can run on smooth as well as on rough surfaces. The rocker-bogie mechanism can cover or can climb the obstacle up to an angle of $35^{\circ}$. By taking some accurate dimensions the actual model of rocker-bogie will climb or it will cover the upcoming obstacle in front of the mechanism with great stability. Also, as the main gun mechanism is implemented on top of the rocker-bogie, we have successfully taken the demonstration of the main gun mechanism, it rotates at $360^{\circ}$ in both clockwise and anti-clockwise directions. This model is not limited to military purpose but it can be used in industries also, and we can use this model for farming purpose also by adjusting some spray like mechanism on the top surface or rocker bogie, with help of that mechanism we can easily distribute fertilizer to the crops in that farm. All over the mechanism is timesaving and the costing is also less. We are therefore happy to state that the calculation of mechanical aptitude proved to be a very useful purpose. There may be some modifications which can be made in the future that is one can implement the wheels in $360^{\circ}$ rotation with help of a motor and that can be done easily for making the quick movement of rocker-bogie in all directions as per requirements.

\section{VIII- FUTURE SCOPE}

As this rocker-bogie mechanism is beneficial in all manner but in future we can do some arrangements in according to make this more beneficial to society and country. As this mechanism is used here for military purpose also it can be used for defense purpose to find bomb as bomb detector with help of some sensor arrangements in the circuit section of the rocker-bogie, also this mechanism can be used as a weapon carrier in military operations. This can be also used as a geological mapping system for unknown surfaces or terrains by providing a GPS system, if the camera is mounted on rocker-bogie then we can simply capture the images that will help to explore the unknown surface. For receiving time to time update of any suspicious area by activating SMS system in the circuit section, we can receive information easily or simply the rocker-bogie send message to defense office to inform suspicious activity in that area. It can be used in industries also for carrying a heavy load on an upper surface of the bogie and it can carry that load or some heavy parts to various sections of industry, because of this the work will be done in speed and time will short for movement and man efforts will also be reduced.

\section{REFERENCES}

[1] D. S. Chinchkar, S. S. Gajghate, R. N. Panchal, R. M. Shetenawar, P. S. Mulik, "Design of Rocker Bogie Mechanism" IARJSET International Advanced Research Journal in Science, Engineering and Technology, National Conference on Design, Manufacturing, Energy \& Thermal Engineering (NCDMETE-2017), AGTI's Dr. Daulatrao Aher College Engineering, Vidyanagar Extension, Karad, Vol. 4, Special Issue 1, January 2017.

[2] B.Babu, N.Dhayanidhi, S.Dhamotharan, "Design and Fabrication of Rocker Bogie Mechanism Geosurvey Rover", August 2018 ISSN: 2455-2631, IJSDR | Volume 3, Issue 8. 
Vol. 6 , No. 10, 2021, PP. 76 - 79

International Journal of Innovations in Engineering and Science, www.ijies.net

[3] Abhisek Verma, Chandrajeet Yadav, Bandana Singh , Arpit Gupta, Jaya Mishra, Abhishek Saxena, "Design of Rocker-Bogie Mechanism", Volume 2, Issue 5, May 2017, International Journal of Innovative Science and Research Technology ISSN No: - 2456-2165.

[4] A. Hafeezur Rahman*, Ameer Malik Shaik, J. Rajesh Kumar, V. Balaguru, and P. Sivakumar, "Design Configuration of a Generation Next Main Battle Tank for Future Combat", Combat Vehicles Research and Development Establishment, Chennai - 600 054, India, Email: hafeezurrahman.a@cvrde.drdo.in,Defence Science Journal, Vol. 67, No. 4, July 2017, pp. 343-353, DOI : 10.14429/dsj.67.11426, 2017, DESIDOC.

[5] Abhaykant Sinha, Reshma Sinha, "Design of StairClimbing Rocker-Bogie Mechanism”, International Journal of Innovative Research in Science, Engineering and Technology, Vol. 7, Issue 7, July 2018, ISSN(Online):2319-8753, ISSN(Print):2347-6710.

[6] S. F. Toha, Zakariya Zainol, "System Modelling of Rocker-Bogie Mechanism for Disaster Relief”, 2015 IEEE International Symposium on Robotics and Intelligent Sensors (IRIS 2015), Procedia Computer Science 76 (2015) 243-249.

[7] M. Vighneshwaran, R. Siddharthaa, G. Vijay and S. Pravin Kumar, "Design of All Terrain Vehicle Using Rocker Bogie Mechanism”, International Journal of Mechanical Engineering and Technology (IJMET), Volume 10, Issue 03, March 2019, pp. 214-219, Article ID: IJMET_10_03_022, ISSN Print: 0976-6340, ISSN Online: 0976-6359. 